\title{
Anti-HuC and -HuD autoantibodies are differential sero-diagnostic markers for small cell carcinoma from large cell neuroendocrine carcinoma of the lung
}

\author{
TOSHIHIDE MATSUMOTO ${ }^{1,2}$, SHINICHIRO RYUGE $^{3}$, MAKOTO KOBAYASHI $^{1,2}$, \\ TAIHEI KAGEYAMA ${ }^{1,2}$, MANABU HATTORI ${ }^{1}$, NAOKI GOSHIMA ${ }^{6}$, SHI-XU JIANG $^{4}$, \\ MAKOTO SAEGUSA ${ }^{4}$, AKIRA IYODA ${ }^{5}$, YUKITOSHI SATOH ${ }^{5}$, NORIYUKI MASUDA ${ }^{3}$ and YUICHI SATO ${ }^{1,2}$ \\ ${ }^{1}$ Department of Applied Tumor Pathology, Kitasato University Graduate School of Medical Sciences; ${ }^{2}$ Department of \\ Molecular Diagnostics, School of Allied Health Sciences, Kitasato University; Departments of ${ }^{3}$ Respiratory Medicine, \\ ${ }^{4}$ Pathology and ${ }^{5}$ Thoracic Surgery, Kitasato University School of Medicine, Kanagawa; ${ }^{6}$ Biomedicinal Information \\ Research Center (BIRC), National Institute of Advanced Industrial Science and Technology (AIST), Tokyo, Japan
}

Received January 26, 2012; Accepted March 5, 2012

DOI: $10.3892 /$ ijo.2012.1405

\begin{abstract}
Aiming to identify novel sero-diagnostic markers for neuroendocrine carcinomas of the lung, the two-dimensional gel electrophoresis-immunoblot method was used to analyze tumor-associated autoantibodies in patients with small cell lung carcinoma (SCLC) and large cell neuroendocrine carcinoma (LCNEC). Several autoantigens were revealed and anti-HuC autoantibody was detected only in sera of SCLC patients. Since $\mathrm{Hu}$ family proteins including $\mathrm{HuC}$ are well-known causes of paraneoplastic encephalomyelitis/ sensory neuronopathy (PEM/SN), the expression of $\mathrm{HuC}$ as well as HuD mRNAs and their proteins was studied in 11 lung cancer cell lines. The expression of $\mathrm{HuC}$ and $\mathrm{HuD}$ mRNAs and proteins was only detected in SCLC- and LCNECderived cells. To validate the existence of anti-HuC and - HuD auto-antibodies, we studied a large number of sera including those from lung cancer patients employing dot blot analysis. Anti-HuC and -HuD autoantibodies were detected only in SCLC cases with or without PEM/SN, and not in the sera of LCNEC patients. The mechanism leading to different anti-HuC and -HuD autoantibody production between SCLC and LCNEC is unclear; however, the results from the present and previous studies suggest that anti-HuC and -HuD autoantibodies are novel differential sero-diagnostic markers for SCLC from LCNEC.
\end{abstract}

\section{Introduction}

Lung cancer is the leading cause of cancer-related death worldwide. Based on the presence or absence of cellular

Correspondence to: Dr Yuichi Sato, Department of Molecular Diagnostics, Kitasato University School of Allied Health Sciences, Kitasato 1-15-1, Minami-ku, Sagamihara, Kanagawa 252-0373, Japan E-mail: yuichi@med.kitasato-u.ac.jp

Key words: autoantibody, $\mathrm{Hu}$, lung cancer, small cell lung carcinoma, large cell neuroendocrine carcinoma neuroendocrine differentiation, lung cancer can be grouped into non-neuroendocrine or neuroendocrine tumors. The former is roughly equal to the non-small cell lung cancer (NSCLC) largely comprising squamous cell carcinoma (SCC) and adenocarcinoma (AD). The latter ranges from low-grade typical carcinoid (TC), intermediate-grade atypical carcinoid (AC), to high-grade small cell lung carcinoma (SCLC) and large cell neuroendocrine carcinoma (LCNEC) $(1,2)$, and the 5-year survival rates for TC, AC, LCNEC, and SCLC were $87,56,27$, and $9 \%$, respectively (2). Similar results were also reported by Garcia-Yuste et al, and the 5-year survival rates for TC, AC, LCENC, and SCLC were 96, 72, 21, and 14\%, respectively (3). These results show that both SCLC and LCNEC are highly malignant and have a similar poor prognosis. Pro-gastrin-releasing peptide (pro-GRP) is a well-known sero-diagnostic marker for SCLC; however, its positive rate is lower in stage I and II (35-45\%) than in stage III (55-70\%) and IV (70-80\%). At present, no specific sero-diagnostic markers for distinguishing SCLC from LCNEC have been reported.

Autoantibodies are antibodies detected in the sera of patients with various autoimmune diseases. They are also frequently observed in the sera of patients with various malignancies even in the early stages, and, thus, the possibilities for them to be used as potential tumor markers have been suggested (4-10). Hanash (11) has described that harnessing the immune response to identify novel cancer biomarkers is an attractive strategy, because the immune system performs biological amplification which is equivalent to a PCR reaction by generating a detectable signal, with antigenic tumor proteins as templates, beginning at an early stage during tumor development when the tumor may be otherwise undetectable. Many tumor-related autoantibodies have been reported in pulmonary carcinomas (12-15). Thus, an exhaustive search for novel tumor-specific autoantibodies, which may serve as early sero-diagnostic markers for cancers, has commenced.

In this study, we detected tumor-associated autoantibodies by immunoblotting based on two-dimensional gel electrophoresis 
(2-DE) from the sera of patients with pulmonary neuroendocrine carcinomas. Identified antigens were further assessed to confirm their specific expressions in neuroendocrine carcinomas by RT-PCR and immunoblotting. Finally, the usefulness of the autoantigens was validated using the sera of patients with various types of pulmonary carcinoma, along with non-cancerous and healthy controls.

\section{Materials and methods}

Cell lines. Six SCLC (N230, N231, H69, H82, Lu130, and N417), two LCNEC (LCN1 and LCN2) (16), two AD (A549 and LC-2/ad), and one SCC (RERF LC-AI) cell line were used in this study. All cell lines were grown in RPMI-1640 (Sigma, Steinheim, Germany) supplemented with $10 \%$ fetal bovine serum, $100 \mathrm{U} / \mathrm{ml}$ penicillin, and $100 \mu \mathrm{g} / \mathrm{ml}$ streptomycin (Gibco, Auckland, NZ). After being washed with phosphatebuffered saline without bivalent ions (PBS-), harvested cells were separated into two gropus, one was fixed in $10 \%$ formalin and embedded in paraffin, and the other was stored at $-80^{\circ} \mathrm{C}$ until use for protein and total RNA extraction.

Sera. Sera from 80 pulmonary carcinoma patients (SCLC: 31 , LCNEC: 7, AD: 21, and SCC: 21) and 21 non-neoplastic lung disease (interstitial pneumonia: 7, tuberculosis: 5, non-lung cancer diseases: 3 , acute inflammation: 1, epithelioid granuloma: 1, cryptogenic organizing pneumonia: 1 , nontuberculous mycobacteria: 1, aspergillosis: 1, inflammatory granuloma: i) patients treated at Kitasato University Hospital. Sera from 26 healthy volunteers were also used as a normal control. All sera were kept at $-80^{\circ} \mathrm{C}$ until use. The SCLCs was further divided into 15 limited and 12 extensive disease cases. This study was approved by the Ethics Committee of Kitasato University School of Medicine. All patients were informed of the aim of the study and gave consent to use their samples.

$2 D$-immunoblotting $(I B)$. Sample preparation and the two-dimensional gel electrophoresis (2-DE) used in this study were described in our previous study (17).

Proteins extracted from the mixture of two LCNECs (LCN1 and LCN2) or the mixture of three SCLCs (N231, H69, and Lu130) were separated by 2-DE. Two pieces of gel were prepared for each sample, one was transferred to a polyvinylidene difluoride (PVDF) membrane (Millipore Corp,. Bedford, MA, USA) for immunoblotting and the other was visualized by coomassie brilliant blue R-350 (CBB) staining (PhastGel Blue R, GE Healthcare, Uppsala, Sweden).

Blotting membranes were blocked with $0.05 \%$ casein/TBS $(0.01 \mathrm{~mol} / 1 \mathrm{Tris}-\mathrm{HCl}, \mathrm{pH} 7.5,150 \mathrm{mmol} / \mathrm{l} \mathrm{NaCl})$ for $30 \mathrm{~min}$ at room temperature (RT). Membranes prepared with LCNEC proteins were reacted with 100-times diluted pooled sera of five LCNEC patients and the membranes with prepared SCLC proteins were reacted with 100-times diluted pooled sera of five SCLC patients, respectively, for $1 \mathrm{~h}$ at RT. The dilution buffer was $0.0025 \%$ casein/TBS-T (TBS containing $0.1 \%$ Tween-20). Then, the membranes were incubated with 1,000times diluted horseradish peroxidase (HRP)-conjugated rabbit anti-human IgG polyclonal antibody (Dako, Glostrup, Denmark) for $30 \mathrm{~min}$ at RT. Finally, signals were developed by stable DAB solution (Invitrogen, Carlsbad, CA, USA).
Protein identification. In brief, protein spots that reacted with patients, sera were excised from 2-DE gels and destained with $50 \%(\mathrm{v} / \mathrm{v})$ acetonitrile $(\mathrm{ACN}) / 50 \mathrm{mM} \mathrm{NH} \mathrm{HCO}_{3}$, dehydrated with $100 \%$ (v/v) ACN, and then dried under vacuum conditions. Tryptic digestion was performed for $24 \mathrm{~h}$ at $37^{\circ} \mathrm{C}$ in a minimum volume of digestion solution containing $0.5 \mathrm{ng} / \mu \mathrm{l}$ sequencing grade modified trypsin (Promega Corp., Madison, WI, USA) and $25 \mathrm{mM}$ Tris-HCl buffer ( $\mathrm{pH}$ 9.0). After incubation, digested protein fragments eluted in solutions were collected, and gels were washed once in $50 \%(\mathrm{v} / \mathrm{v}) \mathrm{ACN} / 5 \%$ trifluoroacetic acid (TFA) and collected in the same tube. Solutions containing digested protein fragments were measured by MALDI-TOF/ TOF MS (autoflex-III; Bruker Daltonik GmbH, Bremen, Germany).

Fragment ion spectra from MS and MS/MS were submitted to MASCOT (http://www.matrixscience.com/) for a database search and the identification of corresponding proteins employing the following database: IPI human 20091026 (86379 sequences; 34740790 residues, http://www.ebi.ac.uk/IPI/IPIhuman.http:// www.ebi.ac.uk/IPI/IPIhuman.html/).

$R T$-PCR. Total RNAs from the above-mentioned 11 lung cancer cell lines were extracted with Isogen (Nippon Gene, Tokyo, Japan) according to the manufacturer's instructions. Primers were designed with Oligo Primer Analysis Software, version 6.0 (Takara Bio Inc, Otsu, Japan) according to HuC and $\mathrm{HuD}$ mRNA sequences $(18,19)$. HuC forward primer: 5'-TGCAAGTTGGTTCGGGACAAG-3' (582-602); reverse primer: 5'-GGCGGATGACTGGTAGAGG-3' (1031-1049). HuD forward primer: 5'-GTCTCTTCGGGAGCATTGGT-3' (415-434); reverse primer: 5'-CCTCTTATCAAAGCGGAT GAA-3' (753-773). PCR was performed with pretreatment at $94^{\circ} \mathrm{C}$ for $2 \mathrm{~min}$ and 30 cycles of denaturation at $94^{\circ} \mathrm{C}$ for $30 \mathrm{sec}$, annealing at $60^{\circ} \mathrm{C}$ for $30 \mathrm{sec}$, and extension at $72^{\circ} \mathrm{C}$ for $30 \mathrm{sec}$. Beta-2-microglobulin was used as an internal control. PCR products were electrophoresed on $3 \%$ agarose gel and stained with ethidium bromide.

$1 D$-immunoblotting. Proteins were extracted from lung cancer cell lines with detergent lysis buffer (20) using an ultra-sonic homogenizer (UH-50; SMT Co., Tokyo, Japan). Each extracted protein $(10 \mu \mathrm{g})$ was boiled and separated by $10 \%$ sodium dodecyl sulfate-polyacrylamide gel electrophoresis (SDS-PAGE) with a constant current at $15 \mathrm{~mA}$. The immunoblotting methods were generally the same to those used for 2D-IB with some modifications. Transferred membranes were blocked with $0.5 \%$ casein/TBS for $30 \mathrm{~min}$ at RT, followed by reaction with 200 -times diluted $\mathrm{HuC}$ - and $\mathrm{HuD}$-positive serum as anti-Hu protein antibody with dilution buffer for $1 \mathrm{~h}$ at RT, because purchased anti-HuC antibody did not show specific reactivity. Then, the membranes were incubated with 1,000-times diluted HRP-conjugated rabbit anti-human IgG polyclonal antibody (Dako) for $30 \mathrm{~min}$ at RT. Finally, signals were developed using Immobilon Western reagent (Millipore Corp.).

Micro-dot blot array. Anti-HuC and - HuD autoantibodies in sera were detected employing the automatic dot blot system, and the micro-dot blot array with a 256-solid pin configuration (Kakengeneqs Co., Ltd., Chiba, Japan) was used. In brief, $1 \mu 1$ 

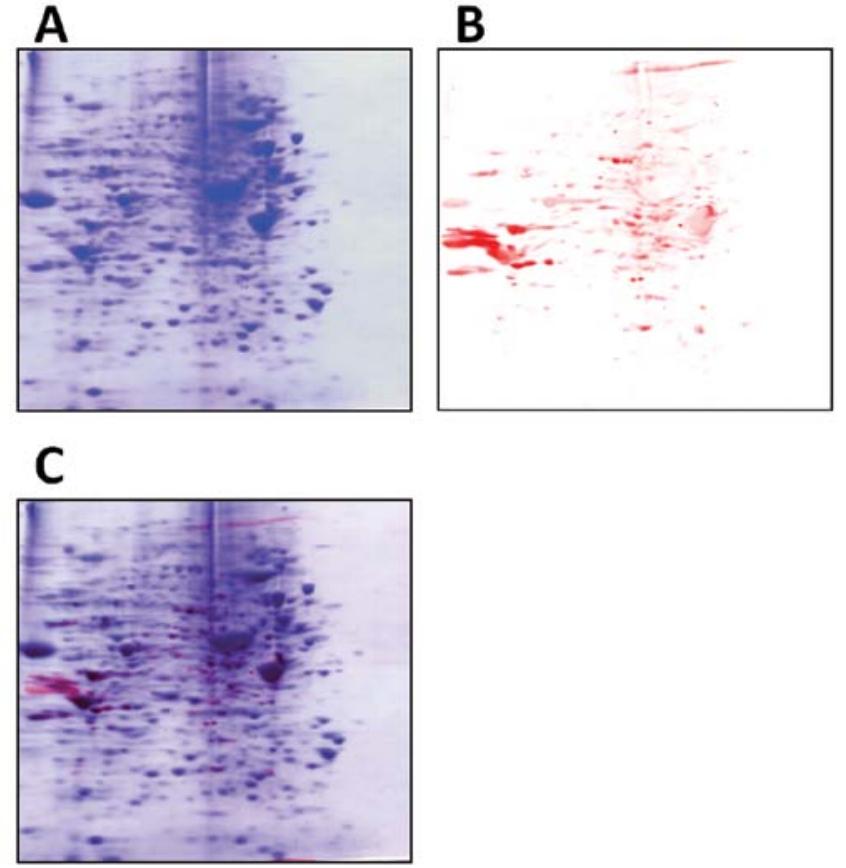

Figure 1. Detection of autoantibodies by 2D-immunoblotting. (A) Protein lysates from SCLC cell lines were separated by 2-DE and stained with CBB. (B) Immunoblot analysis was performed with mixed sera from patients with SCLC as primary antibodies, visualized with DAB solution. (C) A and B were merged. each of proteins was spotted onto PVDF membranes, which were prepared by a wheat germ cell-free system (21). Then the membranes were blocked with 20\% N101 (NOF Corp., Tokyo, Japan)/TBS for $1 \mathrm{~h}$ at RT. After being washed in TBS, the membranes were reacted with 100-times diluted sera with $1 \%$ N101/TBS for $30 \mathrm{~min}$ at RT. After TBS-T washing, the membranes were incubated with 1,000-times diluted HRP-conjugated rabbit anti-human IgG polyclonal antibody for $30 \mathrm{~min}$ at RT. Finally, signals were developed with Immobilon Western reagent. The data were analyzed using DotBlotChipSystem software ver. 4.0 (Dynacom Co., Ltd., Chiba, Japan). Normalized signals are presented as the positive intensity minus background intensity around the spot. Statistical analysis was performed using the Mann-Whitney $U$ test. The area under the curve (AUC) and best cut-off point were calculated employing receiver operating characteristic (ROC) analysis.

\section{Results}

Autoantigen identified by $2 D-I B$. The immunoreactivity of autoantibodies in sera was assessed by $2 \mathrm{D}-\mathrm{IB}$, and the representative positive protein spots on the membrane are shown in Fig. 1. Sixty-two and 63 positive spots were detected with sera from LCNEC and SCLC patients, respectively. In total, 32 proteins for LCNEC and 41 proteins for SCLC were identified as autoantigens. The identified proteins are summarized in Fig. 2. Twenty-three proteins including $\mathrm{HuC}$

\section{A}

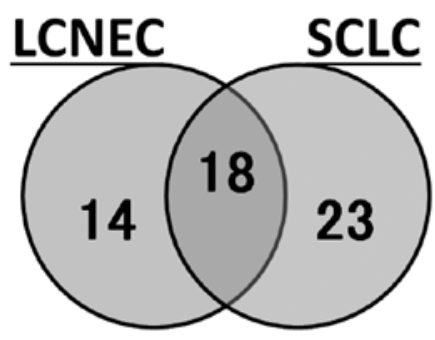

\begin{tabular}{ccc}
\hline Classification & Spots & Antigens \\
\hline LCNEC & 62 & 32 \\
SCLC & 63 & 41 \\
\hline
\end{tabular}

B

\begin{tabular}{|c|c|c|c|c|}
\hline Symbol & Protein & MW & IPI & Molecular Function \\
\hline ATP5A1 & ATP synchase subunit appha, mitochondrial & 59714 & IP100440493 & Transponter activity \\
\hline DRGI & Developmentaly regulsted GTP-binding protein 1 & 40517 & IPI00031836 & Unknown \\
\hline EIF3! & Eukaryoüc transizstion intiation factor 3 subunit I & 36479 & IP100012795 & Transiabion regulater activiny \\
\hline EFFAA1 & Eukaryobc intiaton factor $44 .-1$ & 46125 & IPI00025491 & Translabon regulater activity \\
\hline EFFA2 & Isoform 1 of eukaryctic initation factor $4 \mathrm{~A}-1 \mid$ & 46373 & IPI00328328 & Transiabon regulator activity \\
\hline EZR & Ezin & 69370 & IP100843975 & Cytoskeletal anchoring activity \\
\hline ELAVL3 & Hu antigen $\mathrm{C}$ (HuC) & 39547 & |P100031552 & RNA binding \\
\hline FKBP4 & FK506-binding protein 4 & 51772 & IP100219005 & Iscmerase activity \\
\hline HNRNPK & Isoform 1 of heterogeneous nuclear ribonucleoprotein $\mathrm{K}$ & 50944 & IP100216048 & Ribonucleoprotein \\
\hline FSCN1 & Fascin & 54486 & IPI00163187 & Structura molecule activity \\
\hline HNRPA3 & Isotorm 1 of heterogeneous nuclear ribonucleoprosein $\mathrm{A} 3$ & 39571 & |PI00419373 & RNA binding \\
\hline HFRT1 & Hypoeznthine-guanine phosphoribosytransterase & 24564 & |P100218493 & Enzyme: Ribosyltransterase \\
\hline HSPBOAA1 & Isoform 2 of heat shock protein HSP 90-alpha & 98099 & IPI00382470 & Chaperone activity \\
\hline HSPA1A & Heat shock $70 \mathrm{kDa}$ protein 1 & 70009 & IPI00304925 & Chaperone activiny \\
\hline HSPAB & Isoform 1 of heat shock cognate 71 kDaprotein & 70054 & IP100003865 & Heat shock protein actvity \\
\hline KRTQ & Keratin, type I cytoskeletal 8 & 53871 & IPI00554648 & Structural molecule activity \\
\hline HSPD1 & $60 \mathrm{kDa}$ heat shock protein, mitochondrial & 61016 & IPI00794154 & Heat shock protein activity \\
\hline MDH2 2 & Malate dehycrogenase, mitochondrial & 35481 & IPI00291006 & Catalytic activity \\
\hline PHB & Putative uncharactenized protein PHB & 22723 & IPI00793442 & Receptor signaling complex scaffold activity \\
\hline MSN & Putative uncharacterized protein MSN (Fragment) & 67645 & |PI00872814 & Structural consttuent of cytoskeleton \\
\hline RPSAP15 & RPSA 33 kDa protein (ribosomal protein SA) & 33293 & |P100413108 & Cell adhesion molecule actoity \\
\hline RUVEL2 & RuvB-like 2 & 51125 & IPID0009104 & Transcription regulator activity \\
\hline VTA1 & Vascuolar protein sorting-associated protein VTA1(C6orf55) & 33858 & |P100017160 & Unknown \\
\hline
\end{tabular}

Figure 2. Identified autoantigens in LCNEC and SCLC patients. (A) Compared autoantigens identified in sera from patients with LCNEC or SCLC. Thirty-two and 41 autoantigens were identified from LCNEC and SCLC, respectively. The number of approved autoantigens identified both in LCNEC and SCLC was 18. (B) Twenty-three autoantigens including ELAVL3 (HuC) were identified only in SCLC patients. 
A

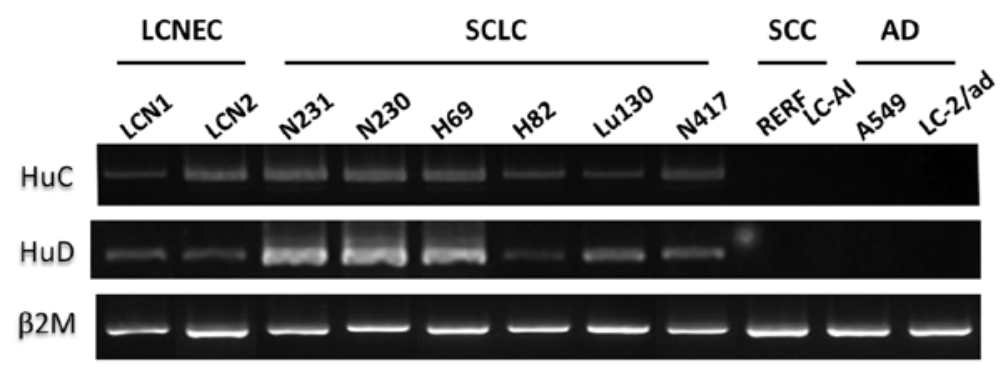

B

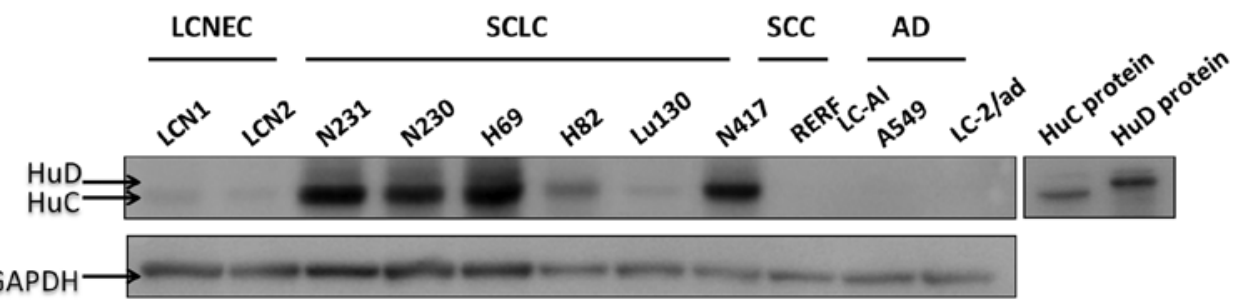

Figure 3. HuC and HuD expressions in lung cancer cell lines. (A) HuC and HuD mRNAs were detected by RT-PCR. Both mRNAs were expressed only in LCNEC and SCLC cell lines. The internal control was beta-2-microglobulin ( $(\beta 2 \mathrm{M})$. (B) HuC protein levels were detected by immunoblot analysis. HuC and $\mathrm{HuD}$ recombinant proteins were used as a positive control and GAPDH was used as an internal control. HuC protein was also expressed only in the majority of SCLC and LCNEC cell lines, and HuD protein was expressed only in a part of SCLC cell lines.

A

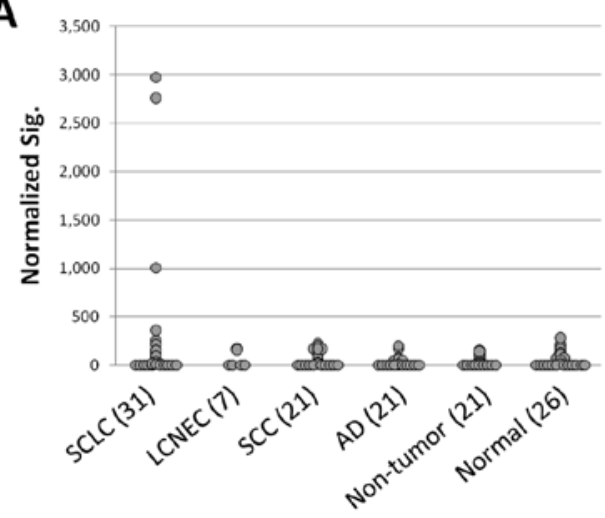

B

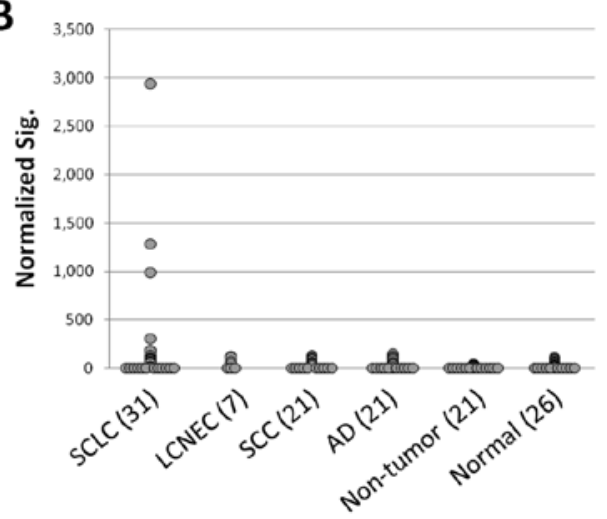

\section{C}

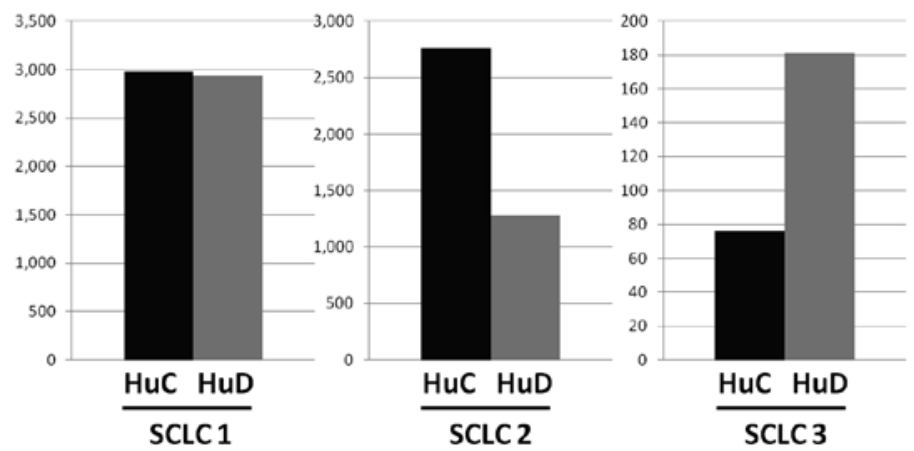

Figure 4. Anti-HuC and -HuD autoantibody levels in sera by dot blot analysis. Anti-HuC autoantibody was detected in 4/31 SCLC patients and not in the others (A). Anti-HuD autoantibody was also detected only in 6/31 SCLC patients (B). The quantitative ratio of anti-HuC and -HuD autoantibodies varied from case to case $(\mathrm{C})$.

were detected only in SCLC, 14 only in LCNEC, and 18 were observed in both.

$H u C$ and $H u D$ expressions in lung cancer cell lines. To examine whether $\mathrm{HuC}$ and $\mathrm{HuD}$ are specifically expressed in neuroendocrine tumors of the lung, we performed RT-PCR using 11 lung cancer cell lines (Fig. 3A). The expressions of $\mathrm{HuC}$ and $\mathrm{HuD}$ mRNAs were detected in all neuroendocrine carcinoma-derived cell lines, but not in SCC or AD cell lines.

To confirm that $\mathrm{HuC}$ and $\mathrm{HuD}$ proteins were also specifically expressed in neuroendocrine tumors, we performed immunoblot analysis using the same 11 lung cancer cell lines (Fig. 3B). 
Both proteins were also detected only in neuroendocrine carcinoma-derived cell lines. HuC protein was detected in 5 of 6 SCLC and the two LCNEC cell lines. HuD protein was also detected in 4 of 6 SCLC, but not in the two LCNEC cell lines. These results were generally in accordance with those of mRNA expression analyses by RT-PCR.

Validation of anti-HuC and $-\mathrm{HuD}$ autoantibodies. To confirm the utility of anti-HuC and -HuD autoantibodies as potential biomarkers in neuroendocrine carcinoma of the lung, we investigated their levels in patient and control sera by dot blot analysis. Anti-HuC autoantibody was detected in 4 of 31 SCLCs (Fig. 4A), but not in other lung cancer subtypes including LCNEC, non-neoplastic lesions, or healthy controls $(\mathrm{p}=0.003)$. At a cut-off point of 360 , the sensitivity for SCLC was $12.9 \%$ (95\% CI: 0.036-0.298). Anti-HuD autoantibody was also detected in 6 of 31 SCLCs (Fig. 4B), but not in the others $(\mathrm{p}<0.001)$. At a cut-off of 176 , the sensitivity for SCLC was $19.6 \%$ (95\% CI: 0.075-0.375). When compared with the others, both anti-HuC and -HuD autoantibodies showed $100 \%$ specificity for SCLC. The AUC-ROC levels were 0.577 and 0.602 , respectively.

Anti-HuC and -HuD autoantibodies are detected in SCLC patients with and without PEM/SN. In this study, these autoantibodies were detected in patients without rather than with PEM/SN. Furthermore, the quantitative ratio of anti-HuC and -HuD autoantibodies varied from case to case (Fig. 4C).

\section{Discussion}

In this study, 55 autoantigens in total were identified employing 2D-immunoblotting. Our results confirmed the utility of this approach to identify tumor-associated antigens including $\mathrm{HuC}$ recognized by autoantibodies in sera from patients with lung cancer $(12,13)$.

$\mathrm{Hu}$ proteins are a family consisting of four RNA-binding proteins, three of which are normally expressed in the nervous system (22). All four members have three RNA-interacting domains known as RRM (RNA recognition motif) (23). PEM/ $\mathrm{SN}$, which occurs in less than $1 \%$ of SCLC patients, is related to high titers of autoantibodies for neuronal $\mathrm{Hu}$ proteins (24-26). The mechanism by which the immune system identifies $\mathrm{Hu}$ proteins from tumor cells as foreign proteins and generates anti-Hu autoantibodies is still unknown. A few studies have focused on the genetic causes of ectopic neuronal $\mathrm{Hu}$ gene (ELAV) expression in neuroendocrine tumors and their roles in the onset and progression of such tumors $(27,28)$. Dalmaou et al (29) and Graus et al (30) reported that approximately $16 \%$ of SCLC patients without PEM/SN have detectable levels of anti-Hu autoantibodies in their sera. In this study, both SCLC patients with and without PEM/SN were detected in $12.9 \%$ for anti-HuC and $19.4 \%$ for $-\mathrm{HuD}$ autoantibodies in their sera. This positive rate was almost the same as those reported previously. In a mouse model study, Kazarian et al found that anti-Hu reactivity appeared to arise prior to chemical evidence of cancer in these mice, suggesting the possibility of using anti-Hu for the early detection of SCLC (31). The present results on anti-HuC and -HuD auto- antibodies supported this possibility, because these autoantibodies were found from limited to extensive diseases. Although the follow-up period was short and only a few controls were used, Tsou et al reported that SCLC patients with high levels of anti-Hu reactivity survived for longer than those with low levels $(p=0.08)(32)$. In agreement with the study by Tsou et al and the present study, Verschuuren et al also reported that anti-Hu-positive SCLC cases survived longer, and Dalmau et al reported that anti-Hu-positive SCLC patients have relatively limited disease $(29,33)$. Larger scale studies are need to classify the reason for the favorable prognosis of SCLC patients with anti-Hu autoantibodies.

In this study, anti-HuC and - HuD autoantibodies were detected only in SCLC patients, and not in those with other lung cancers, non-neoplastic disease, or healthy controls. Although the quantitative ratio of anti-HuC and -HuD antibodies varied from case to case, $23.3 \%$ of SCLC patients were positive for either anti-HuC or anti-HuD or both antibodies. The positive rate may rise using a more sensitive methodology. In spite of this, we detected $\mathrm{HuC}$ and $\mathrm{HuD}$ mRNAs and proteins in LCNECs, and failed to detect anti-HuC and -HuD autoantibodies in the sera of LCNEC patients, who share many biological features with SCLC patients. Although only a small number of cases were analyzed in a previous study, somatic mutations of the $\mathrm{HuD}$ gene were detected in a part of SCLC, TC, and AC cases of different neuroendocrine lung tumors including LCNEC (34). Thus, genetic mutations of $\mathrm{HuC}$ and $\mathrm{HuD}$ may contribute to the production of autoantibodies.

The present results suggest that anti-Hu autoantibodies are differently expressed between SCLC and LCNEC, and they may be used as novel sero-diagnostic and differential markers for these two tumor types.

\section{Acknowledgements}

This work was supported in part by Grants-in-Aid for Third Term Comprehensive Control Research for Cancer conducted by the Ministry of Health, Labor and Welfare of Japan, and Research Project (No. 2010-1001) from the School of Allied Health Sciences, Kitasato University.

\section{References}

1. Travis WD, Linnila RI, Tsokos MG, et al: Neuroendocrine tumors of the lung with proposed criteria for large-cell neuroendocrine carcinoma. Anultrastructural, immunohistochemical, and flow cytometric study of 35 cases. Am J Surg Pathol 15: 529-553, 1991.

2. Travis WD, Rush W, Flieder DB, Falk R, Fleming MV, Gal AA and Koss MN: Survival analysis of 200 pulmonary neuroendocrine tumors with clarification of criteria or atypical carcinoid and its separation from typical carcinoid. Am J Surg Pathol 22: 934-944, 1998.

3. Garcia-Yuste M, Matilla JM, Alvarez-Gago T, Duque JL, Heras F, Cerezal LJ and Ramos G: Prognostic factors in neuroendocrine lung tumors: a Spanish Multicenter Study. Spanish Multicenter Study of Neuroendocrine Tumors of the Lung. Ann Thorac Surg 70: 258-263, 2000.

4. Gautier F, Irminger-Finger I, Grégoire M, Meflah K and Harb J: Identification of an apoptotic cleavage product of BARD1 as an autoantigen: a potential factor in the antitumoral response mediated by apoptotic bodies. Cancer Res 60: 6895-6900, 2000.

5. Old LJ and Chen YT: New paths in human cancer serology. J Exp Med 187: 1163-1167, 1998 
6. Le Naour F, Brichory F, Misek DE, Bréchot C, Hanash SM and Beretta L: A distinct repertoire of autoantibodies in hepatocellular carcinoma identified by proteomic analysis. Mol Cell Proteomics 1: 197-203, 2002.

7. Soussi T: p53 Antibodies in the sera of patients with various types of cancer: a review. Cancer Res 60: 1777-1788, 2000.

8. Stockert E, Jäger E, Chen YT, et al: A survey of the humoral immune response of cancer patients to a panel of human tumor antigens. J Exp Med 187: 1349-1354, 1998.

9. Xia Q, Kong XT, Zhang GA, Hou XJ, Qiang H and Zhong RQ: Proteomics-based identification of DEAD-box protein 48 as a novel autoantigen, a prospective serum marker for pancreatic cancer. Biochem Biophys Res Commun 330: 526-532, 2005.

10. Fernández-Madrid F, Tang N, Alansari H, et al: Autoantibodies to Annexin XI-A and other autoantigens in the diagnosis of breast cancer. Cancer Res 64: 5089-5096, 2004.

11. Hanash S: Harnessing immunity for cancer marker discovery. Nat Biotechnol 21: 37-38, 2003.

12. Yagihashi A, Asanuma K, Kobayashi D, et al: Detection of autoantibodies to livin and survivin in Sera from lung cancer patients. Lung Cancer 48: 217-221, 2005.

13. Vural B, Chen LC, Saip P, et al: Frequency of SOX Group B (SOX1, 2, 3) and ZIC2 antibodies in Turkish patients with small cell lung carcinoma and their correlation with clinical parameters. Cancer 103: 2575-2583, 2005.

14. Brichory F, Beer D, Le Naour F, Giordano T and Hanash S Proteomics-based identification of protein gene product 9.5 as a tumor antigen that induces a humoral immune response in lung cancer. Cancer Res 61: 7908-7912, 2001.

15. Alamowitch S, Graus F, Uchuya M, Reñé R, Bescansa E and Delattre JY: Limbic encephalitis and small cell lung cancer. Clinical and immunological features. Brain 120: 923-928, 1997.

16. Jiang SX, Kameya T, Asamura $\mathrm{H}$, et al: hASH1 expression is closely correlated with endocrine phenotype and differentiation extent in pulmonary neuroendocrine tumors. Mod Pathol 17: 222-229, 2004.

17. Nagashio R, Sato Y, Jiang SX, Ryuge S, Kodera Y, Maeda T and Nakajima T: Detection of tumor-specific autoantibodyes in sera of patients with lung cancer. Lung Cancer 62: 364-373, 2008

18. Sakai K, Gofuku M, Kitagawa Y, et al: A hippocampal protein associated with paraneoplastic neurologic syndrome and small cell lung carcinoma. Biochem Biophys Res Commun 199: 1200-1208, 1994.

19. Graus F and Ferrer I: Analysis of a neuronal antigen (Hu) expression in the developing rat brain detected by autoantibodies from patients with paraneoplastic encephalomyelitis. Neurosci Lett 112: 14-18, 1990.

20. Laemmli UK: Cleavage of structural proteins during the assembly of the head of bacteriophage T4. Nature 227: 680-685, 1970.
21. Goshima N, Kawamura Y, Fukumoto A, et al: Human protein factory for converting the transcriptome into an in vitroexpressed proteome. Nature Methods 5: 1011-1017, 2008.

22. Good PJ: A conserved family of elav-like genes in vertebrates. Proc Natl Acad Sci USA 92: 4557-4561, 1995.

23. Birney E, Kumar S and Krainer AR: Analysis of the RNArecognition motif and RS and RGG domains: conservation in metazoan pre-mRNA splicing factors. Nucleic Acids Res 21: 5803-5816, 1993.

24. Dalmau J, Furneaux HM, Rosenblum MK, Graus F and Posner JB Detection of the anti-Hu antibody in specific regions of the nervous system and tumor from patients with paraneoplastic encephalomyelitis/sensory neuronopathy. Neurology 41: 1757-1764, 1991.

25. Grous F, Keime-Guibert F, Rene R, et al: Anti-Hu-associated paraneoplastic encephalomyelitis: analysis of 200 patients. Brain 124: 1138-1148, 2001.

26. Anderson NE, Cunningham JM and Posner JB: Autoimmune pathogenesis of paraneoplastic neurological syndromes. Crit Rev Neurobiol 3: 245-299, 1987.

27. Carpentier AF, Voltz R, DesChamps T, Posner JB, Dalmau J and Rosenfeld MR: Absence of HuD gene mutations in paraneoplastic small cell lung cancer tissue. Neurology 50: 1919, 1998.

28. Sekido Y, Bader SA, Carbone DP, Johnson BE and Minna JD: Molecular analysis of the $\mathrm{HuD}$ gene encoding a paraneoplastic encephalomyelitis antigen in human lung cancer cell lines. Cancer Res 54: 4988-4992, 1994.

29. Dalmaou J, Furneaux HM, Gralla RJ, Kris MG and Posner JB: Detection of the anti-Hu antibody in the serum of patients with small cell lung cancer-a quantitative Western blot analysis. Ann Neurol 27: 544-552, 1990.

30. Graus F, Dalmou J, Rene R, et al: Anti-Hu antibodies in patients with small-cell lung cancer: association with complete response to therapy and improbed survival. J Clin Oncol 15: 2866-2872, 1997.

31. Kazarian M, Calbo J, Proost N, Carpenter CL, Berns A and Laird-Offringa IA: Immune response in lung cancer mouse model mimics human anti-Hu reactivity. J Neuroimmunol 217: 38-45, 2009.

32. Tsou JA, Kazarian M, Patel A, Galler J, Laird-Offringa IA, Carpenter CL and London SJ: Low level anti-Hu reactivity: a risk marker for small cell lung cancer? Cancer Detect Prev 32: 292-299, 2008.

33. Verschuuren JJ, Perquin M, ten Velde G, DeBaets M, van Breda Vriesman P and Twijinstra A: Anti-Hu antibody titre and brain metastases before and after treatment for small cell lung cancer. J Neurol Neurosurg Psychiatry 67: 353-357, 1999.

34. D'Alessandro V, Muscarella LA, La Torre A, et al: Molecular analysis of the $\mathrm{HuD}$ gene in neuroendocrine lung cancers. Lung Cancer 67: 69-75, 2010. 